\title{
Hızlı Prototipleme Teknolojisi Harç Yığma Yöntemi ile Üretilen Modellerin Ölçüsel Sapmalarının ve Yüzey Pürüzlülüğünün İncelenmesi
}

\author{
Barış ÖZLÜ ${ }^{1 *}$, Okan PISIK ${ }^{2}$, , Halil DEMIR ${ }^{3}$ \\ ${ }^{1}$ Aksaray Üniversitesi Aksaray Teknik Bilimler Meslek Yüksekokulu, Makine Bölümü, Aksaray, TÜRKIYE \\ ${ }^{2}$ TÜBITTAK Savunma Sanayii Araştırma ve Geliştirme Enstitüsü, ANKARA, TÜRKIYE \\ ${ }^{3}$ Karabük Üniversitesi Teknoloji Fakültesi, İmalat Mühendisliği, Karabük, TÜRKIYE
}

Geliş / Received: 02/05/2019, Kabul / Accepted: 20/02/2020

Öz

Bu çalışmada, farklı geometrik toleranslarda ve ölçülerde model tasarımı yapılmıştır. Tasarlanan model, hızlı prototip üretim uygulamalarından harç yığma tekniği kullanılarak üretilmiş̧ir. Model üretimi sırasında farklı uç tipi (katman kalınlığı) ve inşa yöntemleri kullanılmıştır. Modellerin üretiminde ABS M30 malzemesi kullanılmıştır. Üretilen her bir parça üç boyutlu tarama cihazı ile taranarak tasarlanan modellerin geometrik hataları ve ölçüsel sapmaları değerlendirilmiş̧ir. Ayrıca farklı uç tipi ve inşa yöntemlerine göre üretilen modellerin yüzey pürüzlülük değerleri ölçülmüştür. Üretilen ve tasarımı yapılan modellerin geometrik hataları ve ölçüsel sapmalar karşılaştırıldığında ölçü tamlığı, en ince uç tipi olan T10 ve Solid Normal (SN) inşa yöntemi ile üretilen modelde ölçülmüștür. Bununla birlikte T10 uç tipi ve Solid Normal (SN) inşa yöntemi ile üretilen modelde optimum yüzey pürüzlülüğü $4 \mu \mathrm{m}$ olarak ölçülmüştür.

Anahtar Kelimeler: Hızlı prototipleme, harç yığma, ölçüsel sapma, yüzey pürüzlülüğü.

\section{Investigation of Models Produced by Rapid Prototyping Technology Solid Ground Method the Dimensional Deviations and Surface Roughness}

\begin{abstract}
In the study, different geometric tolerances and dimensions model design is made. Designed model, rapid prototype manufacturing applications using solid ground curing technique production is produced. Different tip type (layer thickness) and construction methods were used during model production. Production of models ABS M30 material is used. The geometric errors and the dimensional deviations of the models designed by scanning each piece with three-dimensional scanning device were evaluated. Furthermore, the models produced according to tip type and construction methods were measured surface roughness values. When the geometric errors and dimensional deviations of the models produced and designed were compared, they were measured in the model which was produced by T10 and Solid Normal (SN) construction method which is the thinnest tip type of measurement completeness. In addition, the T10 type and Solid Normal (SN) construction method optimum surface roughness was measured as $4 \mu \mathrm{m}$.
\end{abstract}

Keywords: Rapid prototyping, solid ground, dimensional deviations, surface roughness 


\section{Giriş}

Hızlı prototipleme, üç boyutlu bilgisayar destekli tasarım verilerini kullanarak bir parçanın veya montajın ölçekli modelini hızlı bir şekilde üretmek için kullanılan bir teknikler grubu olarak tanımlanabilir. Hızlı Prototipleme ayrica katı serbest formlu imalat, bilgisayar otomatik imalat ve katmanlı imalat olarak da adlandirılır (Novakova vd., 2012). Yaklaşık otuza yakın hızlı prototipleme tekniği bulunmaktadır. Ancak bu tekniklerden yalnızca birkaçı yaygın olarak kullanılmaktadır. En yaygin hizlı prototipleme teknikleri; Stereolitografi (Stereo Lithography - SLA), Ergiyik Birikimli Modelleme (Fused Deposition Modeling FDM), Tabakalı Parça İmalatı (Laminated Object Manufacture - LOM), Seçici Lazer Sinterleme (Selective Laser Sintering - SLS), 3 Boyutlu Püskürtmeli Bask1 (3D Ink Jet Printing) olarak siralanabilir (Tan vd., 2003, Pham ve Gault, 1998). Hizlı prototipleme tekniklerinden, ergiyik biriktirme modelleme

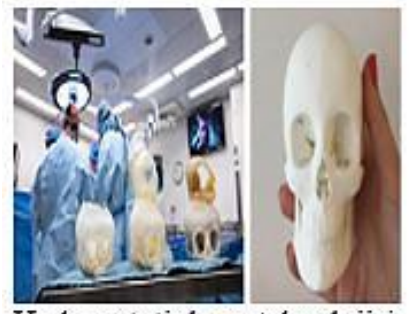

Hizlı prototipleme teknolojisi ile üretilen kafatası parçaları.

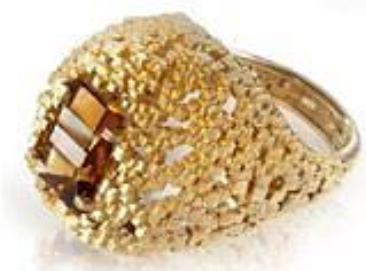

Üç boyutlu yazıcı kullanarak üretilen yüzük

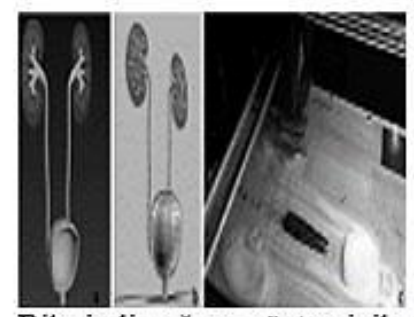

Bileşimli yı̆gma yöntemi ile Cerrahpaşa üriner sistem modelinin PLA filamentten üç boyutlu yazıcıda basilması.

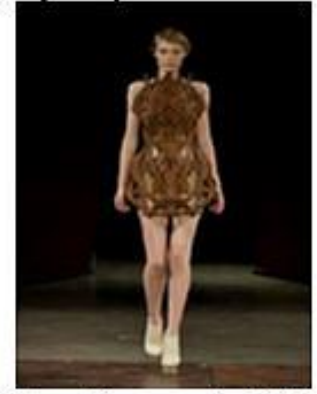

Üç boyutlu yazıcıda bütün olarak üretilen giysi

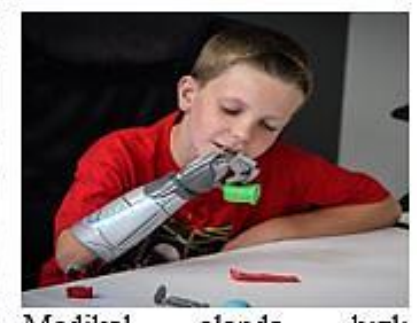

Medikal alanda hizlı prototipleme teknolojisi ile oluşturan protez kol.

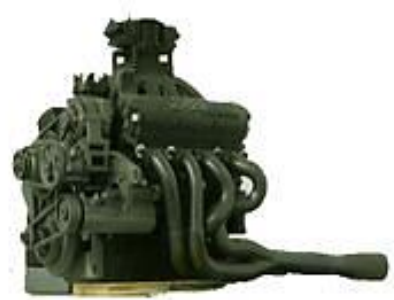

Hizlı prototipleme teknolojisi ile elde edilmiş motor montaj1

Şekil 1. Hızlı prototipleme teknolojisi yardımı ile üretilen farklı ürünler (Emre vd., 2015, Apak, 2010, Yildiran, 2016, Bora, 2018). 
Literatürdeki yapılan çalışmalara bakıldığında, hızlı prototipleme teknolojisi kullanılarak farklı çalışmalar yapılmıştır. Gri Taguchi yöntemi kullanılarak FDM imal edilmiş ABSP400 parçasının boyutsal doğruluğu üzerindeki parça oryantasyonu, örme genişliği, katman kalınlığı, hava boşluğu ve tarama açısı gibi beş işlem parametresinin etkilerini incelemişler (Sood vd., 2009). Biriktirilmiş ABS parçalarının boyutsal doğruluğunu etkileyen kilit faktörleri belirlemek için Taguchi yöntemi ve ANOVA tekniğini uygulamışlardır. Katman kalınlığı, örme genişliği, tarama açısı ve hava boşluğu gibi girdi değişkenleri göz önünde bulundurulmuş. Tabaka kalınlığ 1 ve hava boşluğunun FDM parçalarının doğruluğunu önemli ölçüde etkilediği sonucuna varmışlardır (Nancharaiah vd., 2010). Ergiyik Birikimli Modelleme tekniğinde (FDM) işlem parametrelerinin, ABS malzemesinden üretilen prototipin yüzey pürüzlülügü üzerindeki etkilerini araştırmışlar. $\mathrm{Bu}$ çalışmada Taguchi deney tasarımı, sinyal/gürültü oranı $(\mathrm{S} / \mathrm{N})$ ve varyans analizi (ANOVA) kullanılmıştır. Katman kalınlığı, örme genişliği ve birikme hızını içeren üç işlem parametresi göz önünde bulundurulmuş. $\mathrm{Bu}$ çalışmada, yüzey pürüzlülügüü üzerinde en önemli etkiye sahip olan faktörün, örme genişliği ve hızına göre katman kalınlığının olduğunu ortaya koymuşlar. Ayrıca katman kalınlığı ve yüzey pürüzlülüğü arasında ters bir ilişki olduğu ortaya koymuşlardır (Anitha vd., 2001). Yapılan diğer bir çalışmada, düşük katman kalınlığında üretilen parçalarda daha iyi yüzey pürüzlülüğü elde edilmiş (Azanizawati, 2003). Diğer bir çalışmada ise, FDM teknolojisi ile üretilen parçalarda katman kalınlığının, katman üretim işlemlerinin yüzey kalitesi için en etkili parametre olduğunu belirtmişler, ayrıca yüzey pürüzlülüğü değerlerinin, parçaların farklı üretim açılarına bağlı olduğunu belirtmişlerdir (Ahn vd., 2009).

Yapılan bu çalışmada, CAD ortamında tasarımı gerçekleştirilen bir modelin hızlı prototipleme ile ürün haline dönüşmesi ve bu ürünün tasarıma geri dönütte bulunabilmesi için ölçüsel uygunluğunun ve yüzey pürüzlülüğünü araştırılması hedeflenmiştir.

\section{Materyal ve Metot}

$\mathrm{Bu}$ çalışmada ergiyik yığma modelleme (FDM) teknolojisi, hızlı prototip üretim uygulamalarından harç yığma tekniği ile üretilecek modelin imalatında ABS-M30 filament plastik malzemesi kullanılmıştır. $\mathrm{Bu}$ malzemenin mekanik özellikleri Tablo 1'de verilmiştir.

Tablo 1. Deneylerde kullanılan ABS-M30 filament plastik malzemesinin mekanik özellikleri (Daneshmand vd., 2012)

\begin{tabular}{llcl}
\hline Mekanik özellikleri & Birim & ABS-M30 & Test Metodu \\
\hline Çekme Mukavemeti & Mpa & 36 Mpa & ASTM D638 \\
\hline Özgül Çekme Katsayıs1 & $\mathrm{Mpa}$ & $2413 \mathrm{Mpa}$ & ASTM D638 \\
\hline Çekme Uzamas1 & $\%$ & 4 & ASTM D638 \\
\hline Eğilme Mukavemeti & $\mathrm{Mpa}$ & 61 & ASTM D790 \\
\hline Ĕğme Modülü & $\mathrm{Mpa}$ & 2317 & ASTM D790 \\
\hline IZOD Darbe Çentik & $\mathrm{J} / \mathrm{m}$ & $139 \mathrm{~J} / \mathrm{m}$ & ASTM D256 \\
\hline
\end{tabular}


Deneylerde kullanılacak parçada dairesellik, uzunluk, radius, kanal, çap, pah, düzlemsellik, konum, diklik, açılı yüzeyler gibi çeşitli geometrik unsurlardan oluşacak şekilde CAD modeli oluşturulmuştur. Oluşturulan CAD modelli Şekil 2'de verilmiştir.

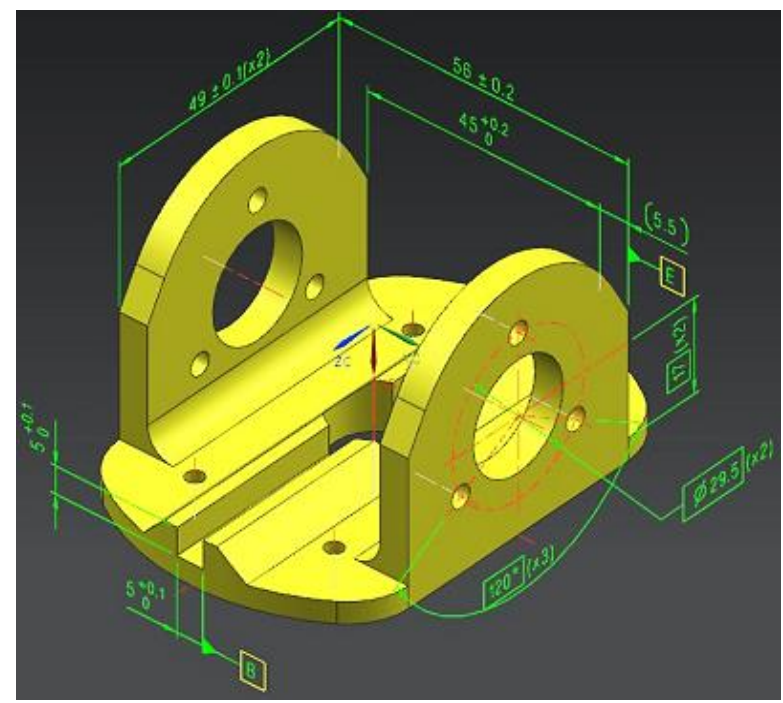

Şekil 2. Yapılan çalışmada kullanılacak modelin $\mathrm{CAD}$ görünümü.
Tasarlanan modeli oluşturmak için dünyada en yaygın şekilde kullanılan ergiyik yı̆̆ma modelleme (FDM) yöntemi kullanılmıştır. Zorlu uygulamalar, yüksek hassasiyetli bask1 ve doğrudan dijital üretimlerde, hassas ve yüksek toleransa sahip parçaların üretilmesi için geliştirilen FORTUS 360 MC Hızlı Prototipleme cihazı ile modellerin üretimleri gerçekleştirilmiştir. Modeller $\mathrm{x}$ ve $\mathrm{y}$ eksenlerin $18000 \mathrm{~mm} /$ dak ve $\mathrm{z}$ ekseni 10000 $\mathrm{mm} /$ dak hızlarında inşa edilmiştir. Üretim sırasında tabla sıcaklığ $190{ }^{\circ} \mathrm{C}$ ve ABS-M30 filament plastik malzemesi için ergitme sıcaklığ $310{ }^{\circ} \mathrm{C}$ olarak belirlenmiştir. Ergiyik yığma modelleme (FDM) yönteminin üretim prosesi Şekil 3'de şematik olarak verilmiştir. Modellerin FORTUS 360 MC Hizlı Prototipleme cihazı ile üretilmesinde malzeme katman kalınlıklarına göre dört farklı uç tipi kullanılmıştır. Malzeme katman kalınlıklarına göre uç tipleri Tablo 2'de verilmiştir.

Tablo 2. Fortus $360 \mathrm{MC}$ prototip uç parametreleri.

\begin{tabular}{ccc}
\hline Model Ucu & Destek Ucu & Katman Kalınlığ \\
\hline T10 & T12 WW & $0.127 \mathrm{~mm}$ \\
\hline T12 & T12 WW & $0.178 \mathrm{~mm}$ \\
\hline T16 & T12 WW & $0.254 \mathrm{~mm}$ \\
\hline T20 & T12 WW & $0.330 \mathrm{~mm}$ \\
\hline
\end{tabular}

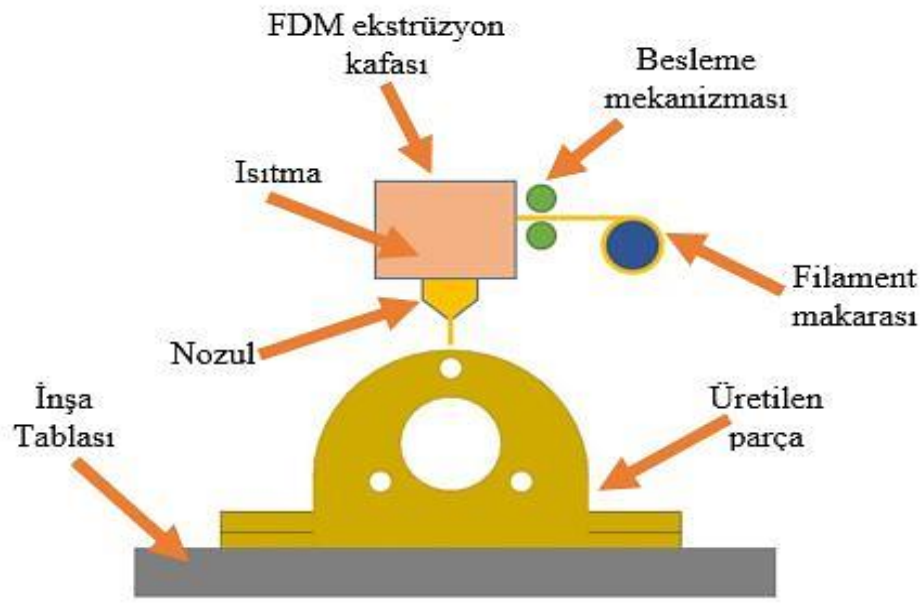

Şekil 3. Ergiyik yığma modelleme (FDM) yönteminin üretim prosesinin şematik görünümü. 
Yapılan çalışmada 12 adet modelin üretiminde dört farklı uç tipi, üç farklı inşa tipi ve sabit inşa açısı kullanılmıştır. Modellerin üretimi sırasında belirlenen parametreler Tablo 3'de verilmiştir. Üretim sırasında model yapısının dayanım ve maliyet unsurlarına göre üç farklı inşa yöntemi mevcuttur. Bunlar Solid Normal (sik tek yönlü yap1), Sparse (tek yönlü yap1) ve Double Sparse (çift yönlü yapı) şeklindedir (Şekil 4). Model örme tekniğinin seçimi ürün inşa zamanını, harcanan malzeme miktarını, modelin ağırlığını ve maliyeti doğrudan etkilemektedir.

Tablo 3. Hızlı prototipleme teknolojisi harç yı̆̆ma yöntemi ile üretilecek modelin üretim parametreleri.

\begin{tabular}{cccc}
\hline \multirow{3}{*}{ Malzeme } & \multicolumn{3}{c}{ Model } \\
\cline { 2 - 4 } & $\begin{array}{c}\text { Model Ucu } \\
(\text { Katman } \\
\text { Kalınlığ1) }\end{array}$ & İnşa Tipi & İnşa Açıs1 \\
\hline \multirow{3}{*}{ ABS-M30 } & T10 & Solid Normal (SN) & \\
& T12 & Sparse (SP) & $60^{\circ}$ \\
& T16 & Duble Sparse (DS) & \\
\hline
\end{tabular}
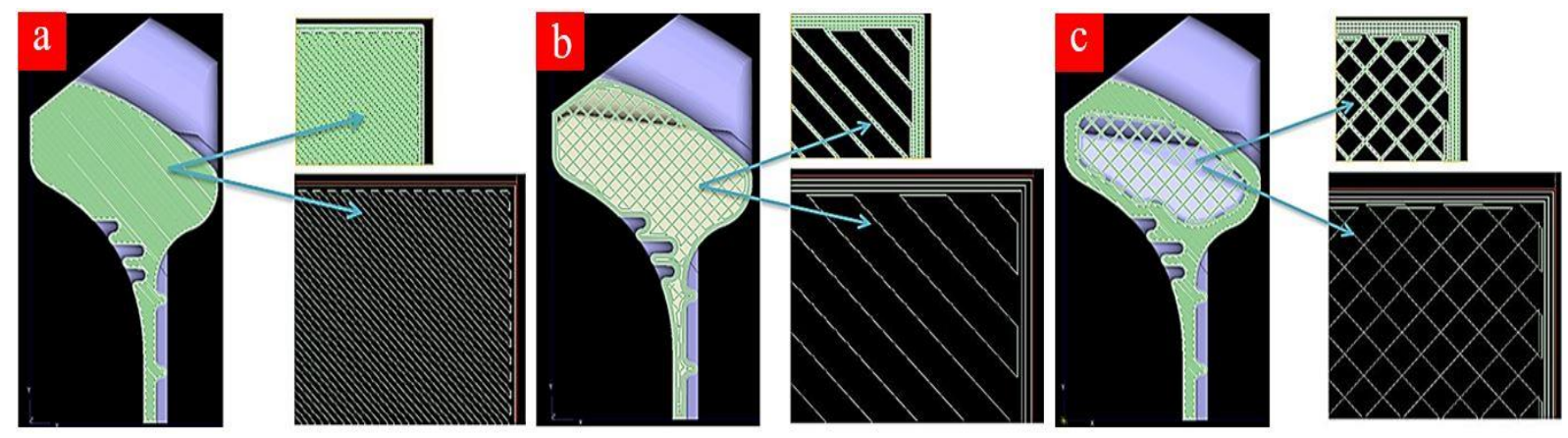

Şekil 4. Deneysel çalışmalarda kullanılan inşa tipleri; a) Solid Normal (sık tek yönlü yapı) b) Saparsa (tek yönlü yap1) c) Duble Saparsa (çift yönlü yap1).

Üç farklı inşa yöntemi ve dört farklı uç tipi kullanılarak FORTUS 360 MC Hizlı Prototipleme cihazı ile üretilen parçalar, ATOS II üç boyutlu tarama cihazı ile üretilen parçaların bütün unsurlarının kamera ve lensler yardımı ile son derece hassas bir şekilde taranarak sayısız nokta bulutu oluşturularak bilgisayar ortamına aktarılmıştır. Katı model ile tarama sonrası elde edilen datalar iç içe giydirilerek, teknik resim 1şı̆̆ında ölçülecek geometri ve ölçülerin seçilmesi, ölçüm sonuçlarının raporlanması
Geomagic Control $\quad \mathrm{X} \quad$ ver.8.1.1 gerçekleştirilmiştir. Deneylerde modellerin yüzey pürüzlülük ölçümleri MITTUTOYO SJ 310 yüzey pürüzlülügü ölçüm cihazı ile gerçekleştirilmiştir. Ölçümler üretilen parçaların düzlemsel yüzeylerin üç farklı ölçümünün ortalamaları hesaplanarak yüzey pürüzlülük $(\mathrm{Ra})$ değerleri belirlenmiştir. Hızlı prototipleme teknolojisi harç yığma yöntemi ile üretilen parçaların deney düzeneği Şekil 5'de şematik olarak gösterilmiştir. 


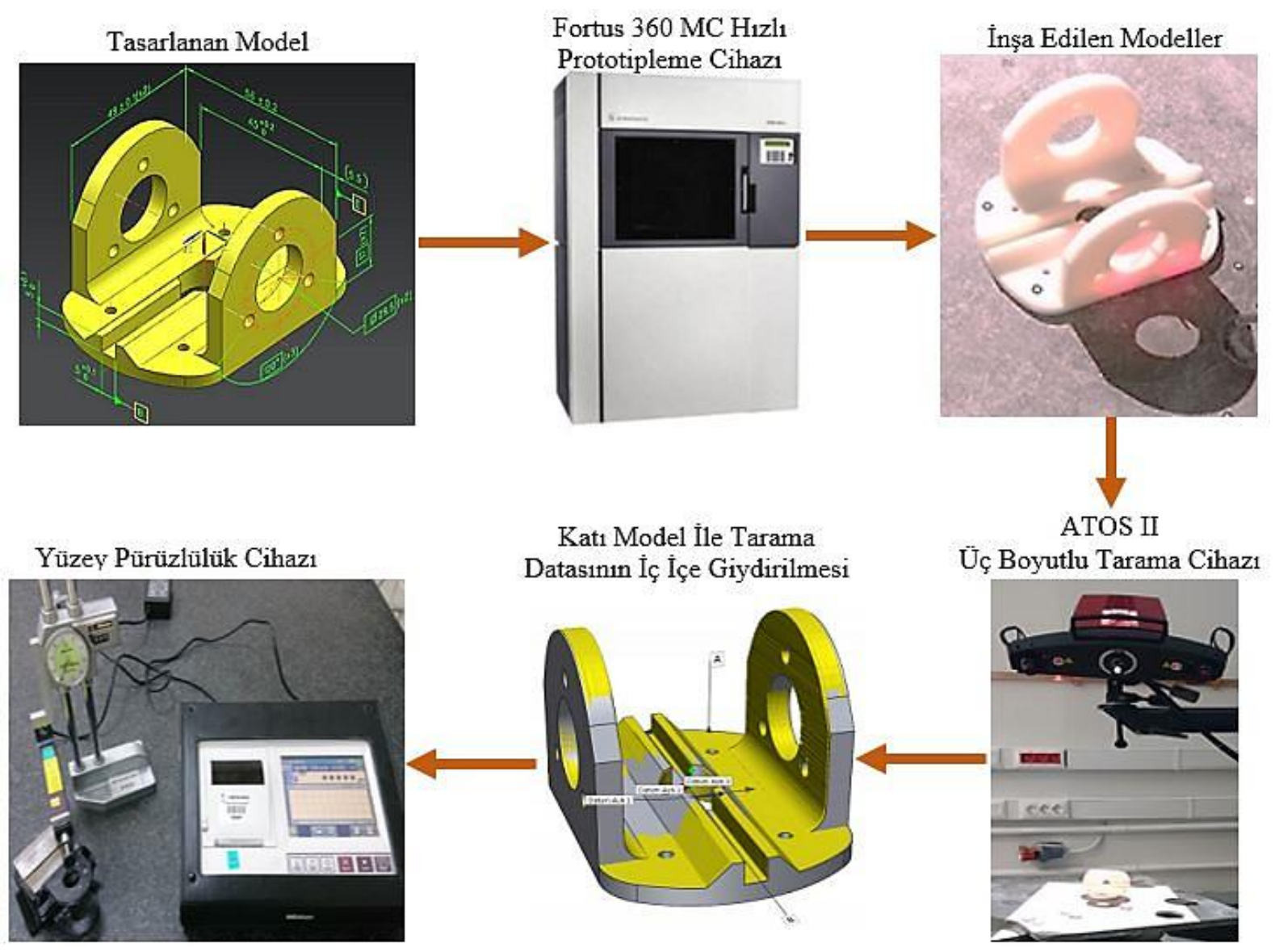

Şekil 5. Deney düzeneğinin şematik görünümü.

\section{Deney Sonuçları}

\section{1. Ölçüsel Sapma Değerleri}

Bu çalışmada tasarımı yapılan model ergiyik yı̆̆ma modelleme (FDM) teknolojisi kullanılarak hizlı prototip üretim uygulamalarından harç yığma tekniği kullanılarak, dört farklı model ucu (T10, T12, T16 ve T20), üç farklı inşa yöntemi (Solid Normal, Sparse ve Duble Sparse) ve sabit uç açısı $\left(60^{\circ}\right)$ ile üretilmiştir. Tasarımı yapılan ve hızlı prototip üretim uygulamalarından harç yığma tekniği kullanılarak üretilen parçalar için farklı uç tipi ve inşa yöntemine göre ölçüsel sapma değerleri Şekil 6'da verilmiştir.

İnşa edilen parçaların bütün yüzeyleri ve tasarımı yapılan modelde belirtilen bütün ölçüleri kapsayacak şekilde tarama işlemleri gerçekleştirilmiştir. T10 uç tipiyle solid normal inşa yöntemiyle üretilen model, tasarımı yapılan modelle \%100 aynı ölçülerde olduğu görülmüştür. T10 uç tipiyle solid normal inşa yöntemiyle üretilen modele göre, sparse inşa yöntemiyle üretilen modelde 0,03 mm'lik sapma ile \%99,97 ve duble sparse inşa yöntemiyle üretilen modelde ise $0,05 \mathrm{~mm}$ 'lik sapma ile \%99,95 ölçüsel yakınlık görülmüştür. T12 uç tipiyle solid normal, sparse ve duble sparse inşa yöntemleri ile üretilen parçaların ölçülerinde sırası ile 0,09 $\mathrm{mm}(\% 99,91), 0,11 \mathrm{~mm}(\% 99,89)$ ve $0,13 \mathrm{~mm}$ $(\% 99,87)$ sapmalar olmuştur. T16 uç tipiyle solid normal, sparse ve duble sparse inşa yöntemleri ile üretilen parçaların ölçülerinde ortalama 0,24 mm'lik bir sapma ölçülmüştür. T20 uç tipinde (katman kalınlığının 0.33 mm 
çıkması) sırası ile solid normal inşa yönteminde $0,33 \mathrm{~mm}(\% 99,67)$, sparse inşa yönteminde $0,39 \mathrm{~mm}(\% 99,61)$ ve duble sparse inşa yönteminde ise $0,44 \mathrm{~mm}(\% 99,56)$ ile en yüksek öçüsel sapma değerleri tespit edilmiştir. Model üretiminde uç tipinin T10'dan T20'ye kadar değişmesi ile uçların katman kalınlığ1 artmıştır. Model inşası sırasında kullanılan uçların kalınlığının arması ölçüsel sapmalar ile paralellik arz etmiştir.
İnşa yöntemlerine göre ölçüsel sapmalar, bütün uçlarda (katman kalınlıklarında) en iyi öçüsel değerler solid normal yöntemi ile inşa edilen modellerde görülürken, en büyük ölçüsel sapma değerleri duble sparse inşa yönteminde görülmüştür. Bunun nedeni solid normal inşa yönteminin, sparse ve duble sparse inşa tekniklerine göre daha sık örme tekniğine sahip olması ölçüsel sapmaların daha az olmasına neden olduğu düşünülmektedir.

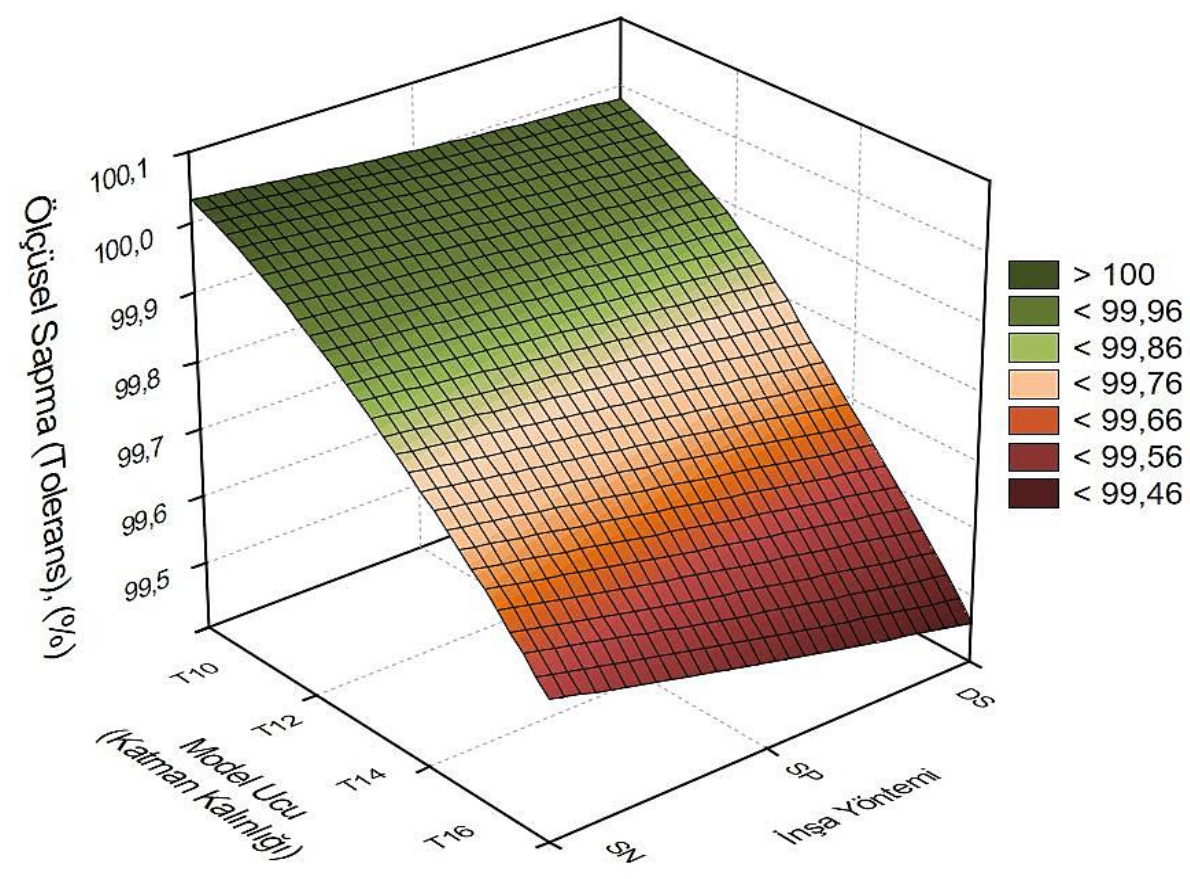

Şekil 6. Hızlı prototip üretim uygulamalarından harç yığma tekniği kullanılarak farklı model ucu ve farklı inşa yöntemi ile üretilen modellerin ölçüsel sapma değerleri.

\subsection{Yüzey Pürüzlülüğüu}

Ergiyik yığma modelleme (FDM) teknolojisi, hızlı prototip üretim uygulamalarından harç yığma tekniği kullanılarak dört farklı model ucu (T10, T12, T16 ve T20), üç farklı inşa yöntemi (Solid Normal, Sparse ve Duble Sparse) ve sabit uç açısı $\left(60^{\circ}\right)$ ile parçalar üretilmiştir. Üretilen her bir model üzerinde belirlenen 3 farklı düzlemsel referans yüzeyi seçilerek bu yüzeylerden yüzey pürüzlülük değerleri ölçülmüştür. Ölçülen yüzey pürüzlülük değerlerinin aritmetik ortalamaları hesaplanarak yüzey pürüzlülük değerleri $(\mathrm{Ra})$ belirlenmiştir.

Şekil 7'de ergiyik yığma modelleme teknolojisi, hizlı prototip üretim uygulamalarından harç yığma tekniği kullanılarak dört farklı model ucu (katman kalınlığı), üç farklı inşa yöntemi ile üretilen parçaların yüzey pürüzlülük değerleri verilmiştir. T10 uç tipiyle solid normal inşa 
yöntemiyle üretilen modelin yüzey pürüzlülük değeri $4 \mu \mathrm{m}$ olmuştur. Uç tipinin (katman kalınlığının) T12, T16 ve T20 olması ile yüzey pürüzlülüğü değerleri sırası ile $\% 37,5$ $(5,5 \mu \mathrm{m}), \% 70(6,8 \mu \mathrm{m})$ ve $\% 87,3(7,49 \mu \mathrm{m})$ oranlarda artma olmuştur. Modellerin üretimi sırasında kullanılan uçların (katman kalınlığı) kalınlıklarının artması ile yüzey pürüzlülük değerlerinin arttığ 1 görülmüştür. T10 uç tipiyle Sparse ve Duble Sparse inşa yöntemiyle üretilen modelin yüzey pürüzlülük değeri, solid normal inşa yöntemiyle üretilen modelin yüzey pürüzlülük değerine göre sırası ile $\% 17,5(4,7 \mu \mathrm{m})$ ve $\% 12,5(4,5 \mu \mathrm{m})$ oranlarda artma olmuştur. T10, T12, T16 ve T20 farklı model uçlarında, sparse ve duble sparse inşa yöntemleriyle üretilen modellerin yüzey pürüzlülük değerleri, solid normal inşa yöntemine göre artma görülmüştür. En iyi yüzey pürüzlülük değerlerinin sira ile solid normal, duble sparse ve sparse inşa yönteminde ölçülmesinin sebebi; solid normal inşa yöntemi modelin dış katmanında çevresel tek döngüde geçmesi ile model inşa dolgusunu sık bir yapıdan oluşturması ile en iyi yüzey pürüzlülüğü elde edilmiştir. Sparse (tek yönlü yapı) inşa yöntemi ile modelin dış katmanın çevresel bir döngüde geçmesi ve yapı inşasının da tek yönde yapılmakta ve örme aralığı diğerlerine göre daha seyrek olması yüzey pürüzlülüğünün kötü çıkmasına neden olmuştur. Sonuç olarak parça üretimi sırasında kullanılan model uç tipi (katman kalınlığı) ve inşa yöntemi üretilen parçaların yüzey kalitesini önemli ölçüde etkilediği görülmektedir.

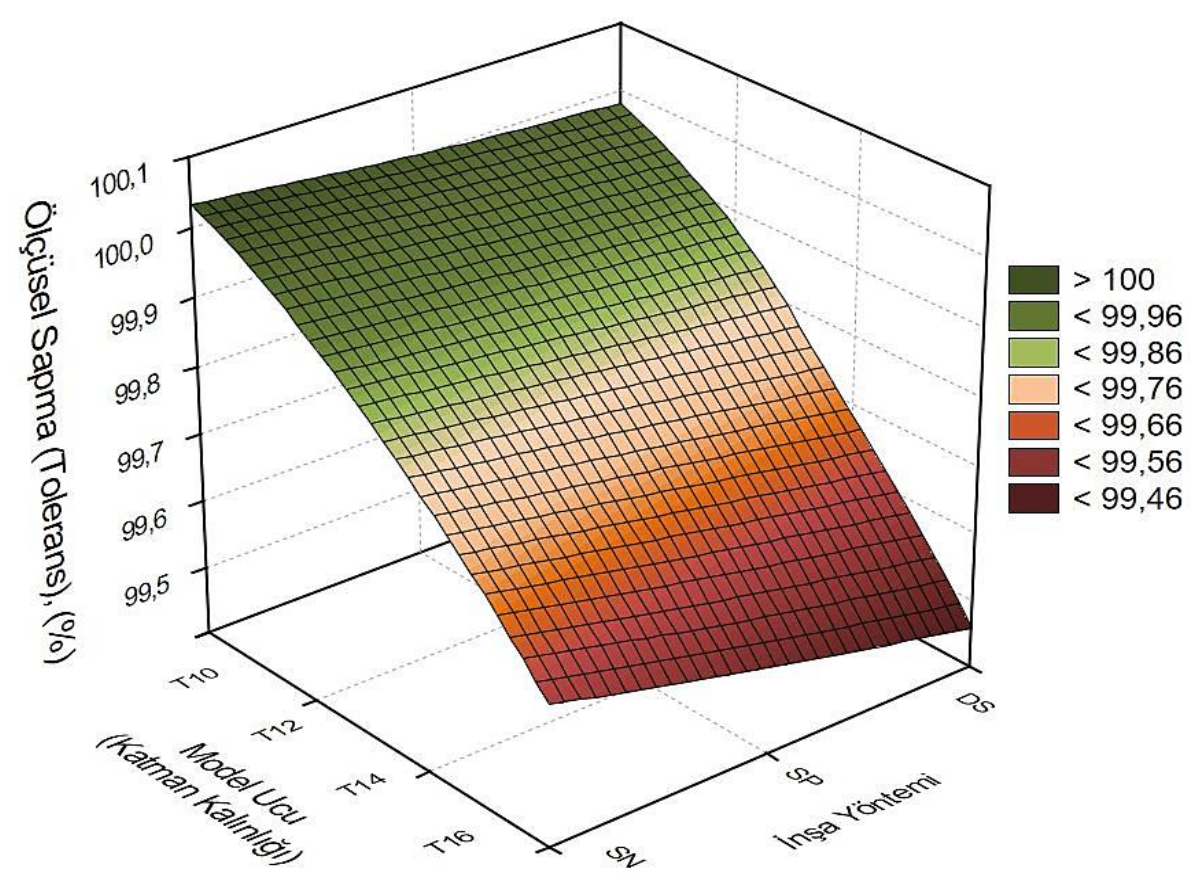

Şekil 7. Hızlı prototip üretim uygulamalarından harç yığma tekniği kullanılarak farklı model ucu ve farklı inşa yönteminin yüzey pürüzlülüğüne etkisi.

\section{Sonuç}

$\mathrm{Bu}$ çalışmada, ergiyik yığma modelleme (FDM) teknolojisi hızlı prototip üretim uygulamalarından harç yığma tekniği kullanılarak dört farklı model ucu (T10, T12, T16 ve T20), üç farklı inşa yöntemi (Solid Normal, Sparse ve Duble Sparse) ve sabit uç 
açısı $\left(60^{\circ}\right)$ ile üretilen parçaların yüzey pürüzlülük değerleri incelenmiştir. Ayrıca üretilen parçalar ile tasarlanan model arasındaki ölçüsel sapmalar analiz edilmiştir. Yapılan çalışmadan elde edilen sonuçlar aşağıdaki verilmiştir.

- T10 model ucu ve Solid Normal inşa yöntemi ile üretilen parça ile tasarlanan model arasında \%100 ölçü tamlığı elde edilirken, T20 model ucu ve Solid Normal inşa yöntemi ile üretilen parça ile tasarlanan model arasında \%0,33'lik bir sapma görülmüştür.

- En büyük ölçüsel sapma T20 model ucu ve duble sparse inşa yöntemi ile üretilen parça ile tasarlanan model arasinda \%0,44 olmuştur.

- En iyi yüzey pürüzlülüğü T10 model ucu ve Solid Normal inşa yöntemi ile üretilen parçada $4 \mu \mathrm{m}$ ölçülmüştür.

- En yüksek yüzey pürüzlülük değeri T20 model ucu ve Sparse inşa yöntemi ile üretilen parçada $8,15 \mu \mathrm{m}$ olmuştur.

\section{Teşekkür}

$\mathrm{Bu}$ çalışmanın gerçekleştirilmesinde laboratuvar imkânlarından faydalanmamızı sağladığı için TÜBİTAK-SAGE teşekkür ederiz.

\section{Kaynaklar}

Novakova Marcincinova L., NovakMarcincin J., Barna J., Torok J., 2012, "Special materials used in FDM rapid prototyping technology application", IEEE, 16th International Conference on Intelligent Engineering Systems, Lisbon, Portugal, 7376.

Tan K.H., Chua C.K., Leong K.F., Cheah C.M., Cheang P., Abu Bakar M.S., Cha S.W., 2003, "Scaffold development using selective laser sintering of polyetheretherketone- hydroxyapatite biocomposite blends", Biomaterials, 24, 3115-3123.

Pham D.T., Gault R.S., 1998, “A Comparison of Rapid Prototyping Technologies", International Journal of Machine Tools and Manufacture, 38(10-11), 1257-1287.

Bozdemir M., 2018, "Silah kabzasının 3B yazıcılarla tasarım ve imalatı", International Journal of 3D Printing Technologies and Digital Industry, 2(1), 57-68.

Emre Ş., Yolcu M.B., Celayir S., 2015, “Üç boyutlu yazıcılar ve çocuk cerrahisi”, Çocuk Cerrahisi Dergisi, 29(3), 77-82.

Apak S., 2010, "Farklı Hizlı Prototipleme cihazlarında Üretilen Parçaların Üretim Zamanı ve Maliyet Açısından Karşılaştırılması", Yüksek Lisans Tezi, Gazi Üniversitesi Teknik Eğitim Fakültesi Makina Ĕgitimi Bölümü Talaşlı Üretim Ana Bilim Dall, Ankara, 22-84.

Y1ldıran M., 2016, "Moda giyim sektöründe üç boyutlu yazıcılarla tasarım ve üretim", Arte Sanat Dergisi, 9(17), 155-172.

Bora M., 2018, "Görsel sanatlar eğitiminde bilgisayar teknolojisinden yararlanma olanakları", İdil Sanat Dergisi, 7(49), 11771189.

Wohlers T., 2012, "Wohlers report 2012: Additive manufacturing and 3D printing, state of the industry", Colorado, USA: Wohlers Associates.

Sood A.K., Ohdar R.K., Mahapatra S.S., 2009, "Improving dimensional accuracy of Fused Deposition Modelling processed part using grey Taguchi method", Materials and Design, 30, 4243-4252.

Nancharaiah T., Raju D.R., Raju V.R., 2010, "An experimental investigation on surface quality and dimensional accuracy of FDM components", International Journal on Emerging Technologies, 1(2), 106-111.

Anitha R., Arunachalam S., Radhakrishnan P., 2001, "Critical parameters influencing the quality of prototpes in fused deposition modelling ", Journal of Materials Processing Technology, 118(1-3), 385-388. 
Azanizawati M., 2003, "Quality assessment of hollow rapid prototyping model”, Master's Thesis, Universiti Teknologi, Malaysia.

Ahn D., Kweon J.H., Kwon S., Song J., Lee S., 2009, "Representation of surface roughness in fused deposition modeling", Journal of Materials Processing Technology, 209(15-16), 5593-5600.

Daneshmand S., Aghanajafi C., Shahverdi H., 2012, "Investigation of rapid manufacturing technology with ABS material for wind tunnel models fabrication", Journal of Polymer Engineering, 32(8-9), 575-584. 